\title{
DESIGN, ANALYSIS AND PROTOTYPE DEVELOPMENT OF RAILWAY WAGONS ON DIFFERENT LOADING CONDITIONS
}

\author{
Shivendra Nandan, Rishikesh Trivedi, Satyajeet Kant, Javed Ahmad, M. Maniraj \\ School of Mechanical Engineering, Galgotias University, \\ Greater Noida, Gautam Buddha Nagar U.P State India.
}

Abstract- Indian Railway is a rapidly growing field of research, and extensive efforts are being spent with the aim of improving the reliability and availability of railway systems and of substantially reducing maintenance costs by switching from time-based to event-driven maintenance policies. This Project is aimed at proving that effective Analysis can be applied also on already existing Railway Wagons \& Tracks. To do this, and focusing on National and International standards, we are going to develop a Designed prototype of Railway Coaches/Wagons for the different loading conditions for optimum dimensions of wagon in consideration with balancing of tracks and platform loading-unloading of Rolling stock System.

With a propose to design, develop, integrate, and test a Prototype of Railway Wagon \& Tracks of Indian Railway that will have a conformable system for transportation of the locomotive/electric Engines. All the components of the Coach or wagon of engine has been rolled out on the track. Where we apply the vibration intensity ultrasonic testing and this allowed to examine them and to assess if damage indexes corresponded to actual faults. A huge amount of data has been collected and it was possible to assess that the overall system cannot be considered as in stationary operation, neither when the train speed is constant nor when the same track is travelled. Many different techniques have been developed and tested with the aim of detecting damages, design optimization via simulation, and material research for the Accident Prevention.

Keywords: Tracks, Dynamic loading, Maintenance, Prototype, Locomotives, Simulation, Balancing, Material Research \& Ultrasonic Testing.

\section{INTRODUCTION}

\subsection{Project background}

Ever since the advent of railways, the rail tracks have been guiding the trains to operate in a safe manner. Further, development ensured that the tracks played an important role in economic aspects of railways. For the passage of the trains along the tracks to be smooth, the tracks need to be perfectly aligned as well as leveled; otherwise, the track irregularities may cause vibrations and oscillations. It has been seen all along that, the major cause of discomfort for passengers has been due to induced oscillation and vibrations. These vibrations and oscillations are also a major source of damage to the laden goods. The traditional dynamic analysis approach for railway vehicles has been based on the assumption that the car body is modeled as a rigid one. It is quite evitable that for such rigid models, the critical positions in context to ride comfort or safety of laden goods are the vehicle extremities, as at these locations the vertical motion of the whole body tends to sum up with the pitching motion of the car body. The results based on above assumptions of rigid body often leads one to believe that vibration issues at the vehicle extremities are more significant and should be addressed with priority. But the possibility of the magnitudes of the acceleration levels at the center of vehicle floor being comparable with those at vehicle extremes cannot be neglected. With an ever increasing demand for logistic support provided by railways, efforts to improve speed in order to facilitate reduction in time for transport operation has received considerable attention. The past two centuries have seen increase in the travel speed from about $50 \mathrm{~km}$ per day by horseback to about $650 \mathrm{~km}$ per day by car or $200-650 \mathrm{~km}$ per hour by using HSR. [1]

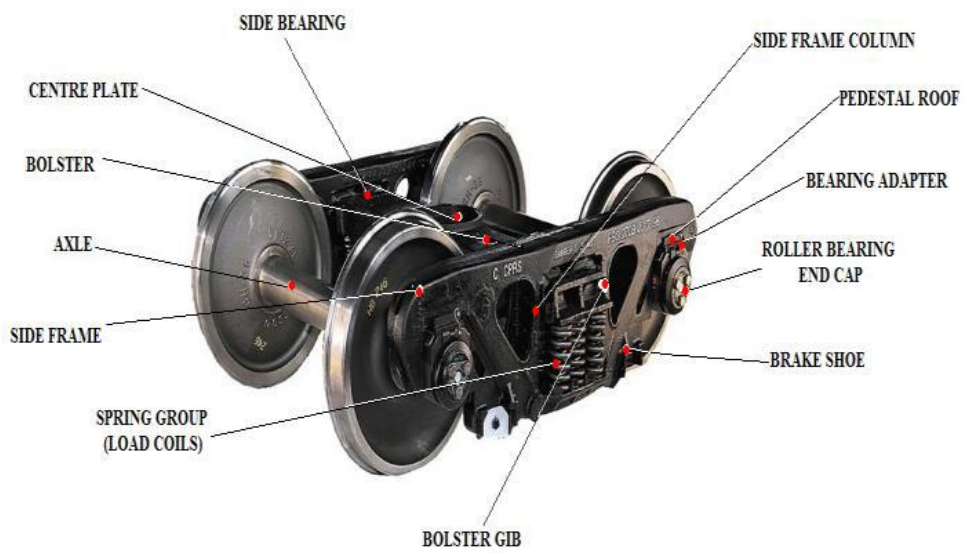

Fig 2.1 Schematic diagram of Railway bogie.

Many of the world's railways face growing demands for both freight and passenger transportation. Recent statistics for 2010 show a growth of worldwide rail freight ton kilometer's by $3.4 \%$ and worldwide rail passenger-kilometers by $3.5 \%$ from the previous year 2010. As for the longer-term outlook, strategic goals and predictions point to continued growth during the coming decades, as exemplified below. In Europe, the European Commission in its 2011 transport white paper sets out strategic goals to transfer freight transportation from road: " $30 \%$ of road freight over $300 \mathrm{~km}$ should shift to other modes such as rail or waterborne transport by 2030 , and more than $50 \%$ by 2050 " [2].

A bogie is a wheeled wagon or trolley. In mechanics terms, a bogie is a chassis or framework carrying wheels, attached to a vehicle. It can be fixed in place, as on a cargo truck, mounted on a swivel, as 


\section{International Journal of Engineering Applied Sciences and Technology, 2020 \\ Vol. 4, Issue 10, ISSN No. 2455-2143, Pages 122-129 \\ Published Online in February 2020 in IJEAST (http://www.ijeast.com)}

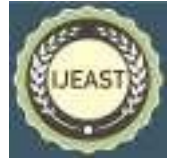

on a train carriage or locomotive, or sprung as in the suspension of a caterpillar tracked vehicle (CTV). A bogie is a structure underneath a train to which wheel axles (and, hence, wheels) are attached through bearings. If they are used there are usually two for each carriage, wagon and locomotive, or alternatively, they are at the connections between the carriages or wagons. The connections of the bogies with the cars allow a certain degree of rotational movement around a vertical axis. Most bogies have two axles, but some cars designed for extremely heavy loads have been built with up to five axles per bogie. Heavy-duty cars may have more than two bogies using span bolsters to equalize the load and connect the bogies to the cars.

Usually the train floor is at a level above the bogies, however, for a double decker train the floor of the car may be lower between bogies to increase interior space while staying within height restrictions [3].

\section{LITERATURE REVIEW}

\subsection{Introduction}

Rail transport is the transport of passengers and goods by means of wheeled vehicles specially designed to run along railways or railroads. Rail transport is part of the logistics chain, which facilitates the international trading and economic growth in most countries [1,2].

A typical railway/railroad track consists of two parallel rails, normally made of steel, secured to cross-beams. The sleepers maintain a constant distance between the two rails; a measurement known as the 'gauge' of the track. To maintain the alignment of the track, it is either laid on a bed of ballast or else secured to a solid concrete foundation, and the whole is referred to as Permanent way [3-5].

Indian railways, the largest rail network in Asia and the world's second largest under one management are credited with having a multi gauge and multi traction system. Indian Railways have been a great integrating force for more than 150 years. It has helped the economic life of the country and helped in accelerating the development of industry and agriculture [6].

From a modest beginning in 1853, when the first train steamed off from Mumbai to Thane covering a distance of $34 \mathrm{kms}$, since then there has been no looking back. It is interesting to note that though the railways were introduced to facilitate the commercial interest of the British it played an important role in unifying the country. Indian railways have grown into a vast network of 7, 031 stations spread over a route length of 63, 221 $\mathrm{kms}$ with a fleet of 7,817 locomotives, 5,321 passenger service vehicles, 4, 904 other coaching vehicles and 228, 170 wagons as on 31st March 2004.

Railways are ideally suited for long distance travel and movement of bulk commodities. Regarded better than road transport in terms of energy efficiency, land use, environment impact and safety it is always in forefront during national emergency.

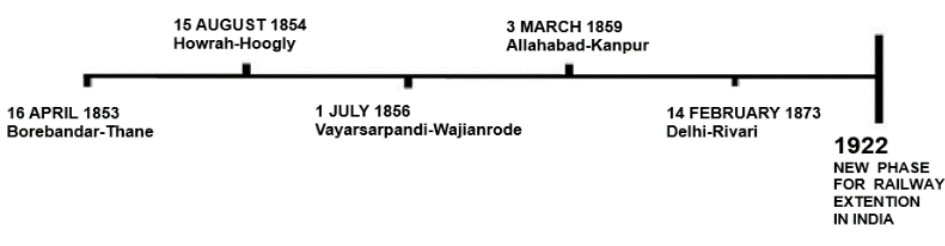

Fig. 2.2: Railways-A Brief History.

The track kilometers in broad gauge $(1676 \mathrm{~mm})$ are $86,526 \mathrm{kms}$, meter gauge $(1000 \mathrm{~mm})$ of $63,028 \mathrm{kms}, 16,001 \mathrm{~km}$ are electrified.

\subsection{Reviews}

[3] B. Vinod Kumar et al. reviewed Prediction of Dynamic behavior of Railway vehicle by using prototype is very costly, lengthy and tedious task. Using virtual prototype of railway model and running it in virtual environment for predicting dynamic behavior of railway vehicle model. At present steel material is used for hopper wagon, these are going to be replaced by aluminum alloy in the nearest future. To increasing load carrying capacity of freight wagons, to reduce self-weight of freight wagon to reduce fuel required, to increase speed of the train in tangent track and in curve passing, to increase comfort and safety of passenger coach. "B. Vinod Kumar et al. (2017)"

[4] Krason Wieslaw et al. reviewed special wagon with a low rotatable loading platform for transportation. Allows quick and fast loading and unloading without any platform infrastructure or terminals. Process of loading and unloading the trailers can be performed considering a whole train or individual wagons from any part of the train (no cranes needed). To save time and money for road transport \& reduction of the negative impact on the environment as well as an increase of road safety by reducing the number of vehicles on the roads. A strength test of the wagon structure was carried out \& complete structure was estimated. For this purpose, numerical analysis was used. Applying repeatable wagons-platforms with an automatic rotating body for fast, safe and easy loading and unloading of trucks Dynamic analyses of the construction in different stages of its development were also carried out. Tests assume that a given system is composed of many stiff modules joined with kinematic constraint. Individual modules of the system are joined with a kinematic pair meant as an additional internal constraint in the form of moving joint. Determines a number of degrees of freedom. All the modules constitute one system defined as a multi-body system. The elements of the lock, in the close configuration are loaded mainly with longitudinal tensile and compressive forces. The purpose of the joint is also to relieve the central node, used mainly for positioning and rotation loading platform of the wagon. "Krason Wieslaw et al. (2016)"

[5] S. V. GANORKAR et al. reviewed that Modern express trains in India face the problem of having a higher floor level than the current platform level. It is also seen in new rakes and coaches that there is a substantial gap in between the train floor and the platform. A simple construction of platform risers and gap fillers can make a huge difference. So from above problems, the solution is to use of platform based ramps, platform based lifts, vehicle based ramps, vehicle based lifts, vehicle based internal lifts, etc. It is a good time to pause and reassess our strategy for providing sustainable. Assured and preferred logistics services to the nation and contribute towards nation building. As Improving overall customer satisfaction, Improving Reliability of Assets and Punctuality of Trains, Lowering 


\section{International Journal of Engineering Applied Sciences and Technology, 2020 Vol. 4, Issue 10, ISSN No. 2455-2143, Pages 122-129 \\ Published Online in February 2020 in IJEAST (http://www.ijeast.com)}

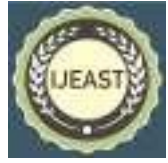

unit cost of operation for passenger and freight transports, to improve margins and providing room to man oeuvre competitive rates and services, Revenue enhancement by increasing modal share of Railways in Passenger and Freight transportation, Improving Cleanliness in Trains and at Stations, Enhancement in Security to prevent theft, pilferage and sabotage, To develop design of new efficient wagons for upcoming transportation commodities like fly-ash, agricultural produce, milk, two wheelers etc. for Indian Railways necessary to original innovative design solutions for Wagons for efficient loading/ unloading and transportation of new traffic commodities. "S. V. GANORKAR et al. (2017)"

[6] A.S. XUE et al. reviewed that Constraint effects of the interference fits between wheels - axle and bearings - axle. Integrated wheelset model of finite element method to calculate the axle stresses. Maximum stress section is at outer side close to wheel seat, different from the prediction of inner side close to wheel seat by the code analytic method. The loads set is constructed from the vehicle dynamic behavior of the mass $\mathrm{m} 1$ above each wheelset with a vertical dynamic factor $\alpha \mathrm{v}$ and a lateral dynamic factor $\alpha \mathrm{H}$, which are respectively defined as 1) The stresses are not symmetrically by the axle central lateral section (ACLS) along track direction. Bigger stresses are inclined to the side with bigger loads of the wheelset.

2) The stresses are also not symmetrically by the axle vertical longitudinal section along axle axis. This is mainly due to effects from the two longitudinal braking forces on the wheel treads.

3) The stresses are still not symmetrically by the axle horizontal longitudinal section along axle axis. Bigger press stresses are inclined to the bottoms of sections. This should be mainly from the gravity effect. "A.S. XUE et al. (2013)"

[7] Stanislav Hodas et al. reviewed that the routes shown in the 3D model terrain surface. A designer that designs reconstruction, modernization or newly built railway tracks must consider the 3D design of digital design documentation and design parameters of the currently valid standards. The design parameters of the railway line project and the optimized location of this track body are closely related. The track designer must also consider the weight which will be transported on the track. The design works include complicated procedures, while the railway track components must comply with all design criteria of the currently applicable standards and regulations. The directional curvature of railway track including basic specifications of its structural elements such as curve radii (blue), shape and length of transition spirals (green), straight sections between the curves (red), etc., must be consistent with the design values of railway track according to STN or STN EN. "Stanislav Hodas et al. (2015)"

[8] D. Peng et al. reviewed that a hopper wagon is a type of railroad freight car used to transport many types of materials such as coal, ore, grain, ballast and minerals and bulk cargo etc. In any such analysis the stress intensity factors at crack tips are important parameters for estimating both residual life and criticality (residual strength). The advantage of the present approach is that it negates the need to explicitly model cracks. A crack of any size can be analyzed using the original (uncracked) finite element model. It is a complicated welded structure. The methodology outlined in this paper requires a knowledge of the uncracked stress distribution in the component which contains a crack. In the process of crack propagating from its initial length up to the critical crack length the cracks can grow in three stages. "D. Peng et al. (2016)"

[9] Vladimir Milovanovic et al. reviewed that it describes a methodology used to identify causes of cracking nearby the welded joint on the underframe of wagon type Symons for the transportation of containers and swap. The aim of this analysis is to identify and register the residual stresses that appear after the process of mounting of the under-frame bottom part. The analysis was done to discover kind of loads which induce cracks in the welded joints. "Vladimir Milovanovic et al. (2015)"

[10] Mehdi Koohmishi et al. reviewed that Ballast layer as sleeper support is a conventional railway track structure to transmit the train load into the underlying base courses as well to drain water outward to the track structure. Ballast fouling influence the mechanical response of ballast materials by decreasing the shear strength of this layer and consequently reducing the stability of the railway track structure. Contaminated ballast produces by adding sand to the clean aggregate sample, physical properties of considered ballast material as well as rounded river aggregate. Each permeability test require approximately 3 hour to complete is specimen is first saturated for 24 hour prior to conducting the permeability test. The Effect of initial gradation of clean ballast as well as size of folding materials on the permeability of sand fouled railway ballast. "Mehdi Koohmishi et al. (2018)"

[11] Lukas Lestinsky et al. reviewed that Noise reduction in railway vehicles is possible to achieve in multiple ways Proper maintenance of the railway vehicle is very important as well. In general, it is very difficult to identify noise from basic variables and technical drawing documentation Role of the simulation methods is to approximate to real life circumstances, which are seen in environment/nature. Simulation methods often use software with mathematical models, mostly derived from empirical formulas which were obtained from experiments. Noise and vibration experiments are very important for noise reduction of railway vehicles. Special role for the task fulfills modern FFT analyzers and manually-operated analyzers (digital acoustic measurement instruments). Record of noise levels - minimal, maximal, levels with different time characteristics and different weight filter during every measurement. "Lukas Lestinsky et al. (2019)"

\section{PROBLEM DESCRIPTION}

Presently, the non-containerized payload carried by Indian Railways is largely dominated by Coal, Iron Ore, Cement, Steel Products, Fertilizers, Petroleum products, etc. These lines of businesses are stagnating and Indian Railways is considering alternate commodities for transportation across the countries. Some such commodities are to cater to such emerging markets, Indian Railways requires new designs of wagons to ensure that the emerging business is not lost to other modes of transportation. The Project is to innovative design for solutions for Wagons for efficient loading/ unloading and transportation of new traffic commodities. The solution should include the design and efficient method of loading and unloading of commodities for safe handling and swift turnaround duly maximizing the transport of commodities per unit time and cost, taking into account the current constraints of fixed infrastructure. 


\section{International Journal of Engineering Applied Sciences and Technology, 2020 \\ Vol. 4, Issue 10, ISSN No. 2455-2143, Pages 122-129 \\ Published Online in February 2020 in IJEAST (http://www.ijeast.com)}

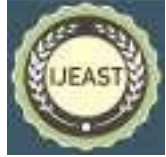

\subsection{Area: Design Analysis and Prototype Development}

3.2 Title: Design, Analysis \& Prototype Development of Railway Coaches (or) wagons on different loading conditions for optimum dimensions of coach in consideration with balancing of tracks \& Platform loading-unloading system.

3.3 Aim: Design of Railway Coach/Wagon by To Develop an efficient Prototype model of Modern Rail for effective Transportation.

\subsection{Motivation:}

- Need of improvement of Design for Sustain and Economical Factor.

- Material Research such as Aluminum which has more strength.

- Reduce Delays of Train Schedules

- Accident Prevention by Vibration Intensity Ultrasonic Testing

- Up gradation in the guide lines of Standards and Specifications for Railway Wagons.

- Due to increase in the population, Need in Design Improvement for Optimum space availability and Comfort of Passenger.

\subsection{Problem description}

All developing or developed countries requires newlystandardized Transport for daily transportation of passenger, Goods, Industrial raw materials and Produced products in almost all cities by means of Railway Transport. Because the increase in use, most existing systems are not sustainable and economical for Transportation. Because of Lack of innovation in railway and also old guide lines of Standards and Specifications for Railway Wagons. As well as Due to increase in the use of railway as transport method causes less space availability, Accidents, Noise causes, Cracks due to Vibration and Delays in loading-unloading scheduling.

In the current scenario of Indian Railway -

- Less Track Maintenance and Poor state of Track Lines.

- Railway Accidents Due to Wagon Design Balancing Of tracks.

- Lack of modern techniques used in the Design and BluePrints Preparation.

- Less strength of Single tracks with respect to WeightSpeed ratio of Trains.

- Because of Lower Track Strength and heavy Wagons Speed reduces of trains and Delays in Train Timing Schedules.

In this Project, We are using virtual prototype of railway model and running it in virtual environment for predicting dynamic behavior of railway vehicle Wagon model. At present steel material is used for hopper wagon these are going to be replaced by aluminum alloy in the nearest future.

The Problems related to railway wagon is eliminated by
- Use of low rotatable loading platform with an automatic rotating body

- To use of platform-based ramps, platform-based lifts, vehiclebased ramps for providing sustainable, assured and preferred logistics services.

- Increasing average speeds of passenger and freight trains and reducing overall transit time By Finding Optimum WeightSpeed ratio.

- with intensive utilization of existing assets and efficient management of constraints

- Integrated wheelset model of finite element method to calculate the axle stresses

- Consider the weight which will be transported on the track.

- Analysis the stress intensity factors at crack tips are important parameters for estimating both residual life and criticality (residual strength).

- Identify causes of cracking nearby the welded joint on the underframe of wagon type Symons for the transportation of containers and swap.

- Conducting Noise and vibration experiments for noise reduction of railway vehicle

- This ultimately increases the Life Cycle of Railway wagons with enhanced safety features.

\subsection{Objective of Project}

The main aim of this project is to develop much cleaner costeffective way of power generation method power generation and accident prevention by vibration intensity ultrasonic testing and which also helps in automatic unmanned railway gate controlling as well as moving platform-based stock rolling loading and unloading system.

Prediction of Dynamic behavior of Railway vehicle by using prototype is very costly, lengthy and tedious task so, now a day most of the railway companies and researchers are using virtual prototype of railway model and running it in virtual environment for predicting dynamic behavior of railway vehicle model.

There is some popular software available for modelling like auto cad \& pro-e, predicting dynamic behavior of vehicle model such as Ansys, Universal Mechanism etc. At present steel material is used for hopper wagon, these are going to be replaced by aluminum alloy in the nearest future. In present work, I have designed and assembly of a proto type model of fright hopper wagon using CAD application In PRO-E or CATIA software etc.

We will perform linear mode shape modelling and design by hopper wagon on track. As the aluminum alloy has greater strength and less self-weight, less fuel will be used in transportation and vertical force is reduced, hence less wear.

\section{RESEARCH PURPOSE AND MEANING}

The purpose of the new wagon design was to maximize the versatility of the concept to allow containers, swap bodies, Passenger trains and trailers to be moved freely on a common form of rail vehicle within most of the standard gauge rail network in Transport. Existing wagons were less versatile in relation to their ability to accommodate a mix of inter-modal modules (IMM). The new design has much greater versatility.

- Decrease in capital cost of railway by optimum design. 


\section{International Journal of Engineering Applied Sciences and Technology, 2020 \\ Vol. 4, Issue 10, ISSN No. 2455-2143, Pages 122-129 \\ Published Online in February 2020 in IJEAST (http://www.ijeast.com)}

- To get More Space availability in the Coaches.

- Using material research selection which can give higher strength with reduce weight of the Wagon.

- Continuous Ultrasonic testing of track

- For Checking of cracks and Balancing of tracks.

- Suitable Transport Design for Increasing Population.

- Reducing Vibration of wagon as well as Tracks at High speeds.

- To Find Optimum Variables on Different type of matter transportation (Such as Oil, CNG Gas, Coal, Pesticides and Passenger Transport.

- Get best speed and load ratio on various condition of weather (i.e. winter, summer, Spring Season, Rainy Days etc.).

\subsection{Components of railway wagon}

- It comprises the Bogie frame.

- The bogie frame has the Axle and wheel arrangements.

- The SUSPENSION system.

- The BRAKING system.

\subsection{Assembling of railway wagon}

Hopper wagons can only be unloaded by gravity with no external assistance and are therefore also classed as selfdischarging wagons. The majority may be filled, when at rail or road level, by high-level discharge chutes (whose ends are more than $70 \mathrm{~cm}$ above the top of the rails) or conveyor belts.

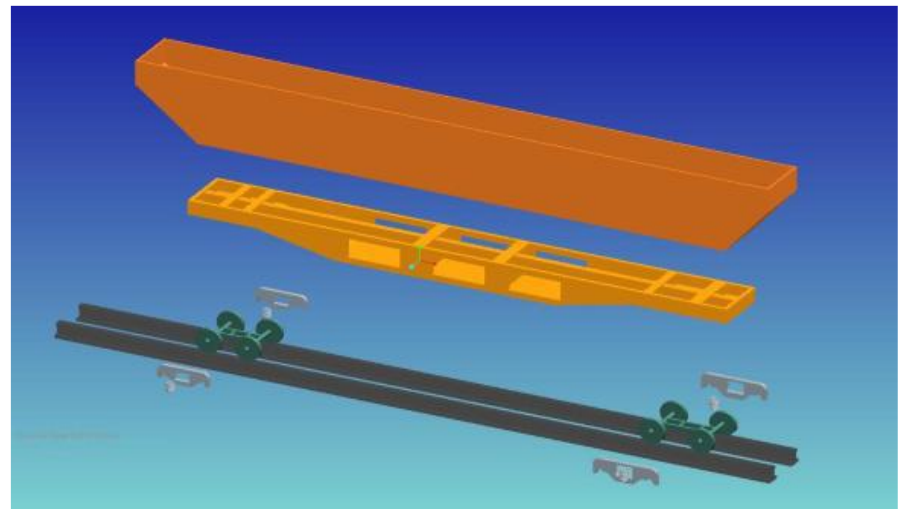

Fig 4.1 Assembled parts of wagon by using software.

Because a controlled amount of the load can be discharged at any place the wagons may be sent anywhere and are even used individually. Railway companies also use hoppers as departmental wagons in maintenance of way trains for ballasting the track.

\subsection{Analysis and Simulation}

In present work, hopper wagon can be made of different Materials like steel and aluminum analyzed by
a) Dynamic Analysis
b) Static Analysis

The step followed is as under:
1. Modeling
2. Assigning Material properties
3. Boundary Conditions

The material properties assigned for hopper wagon are considered by density values.

Modeling: according to dimensions the model of hopper wagon made up of steel and aluminum, the mass momentum of the car body, wheel axle set are been designed by using pro/e software and cad software. From the comparison of steel and aluminum material hopper wagon alloy of these two gives the best result of having the liter weight, less stress acting is acting due to this the train is going to move in the safe way.
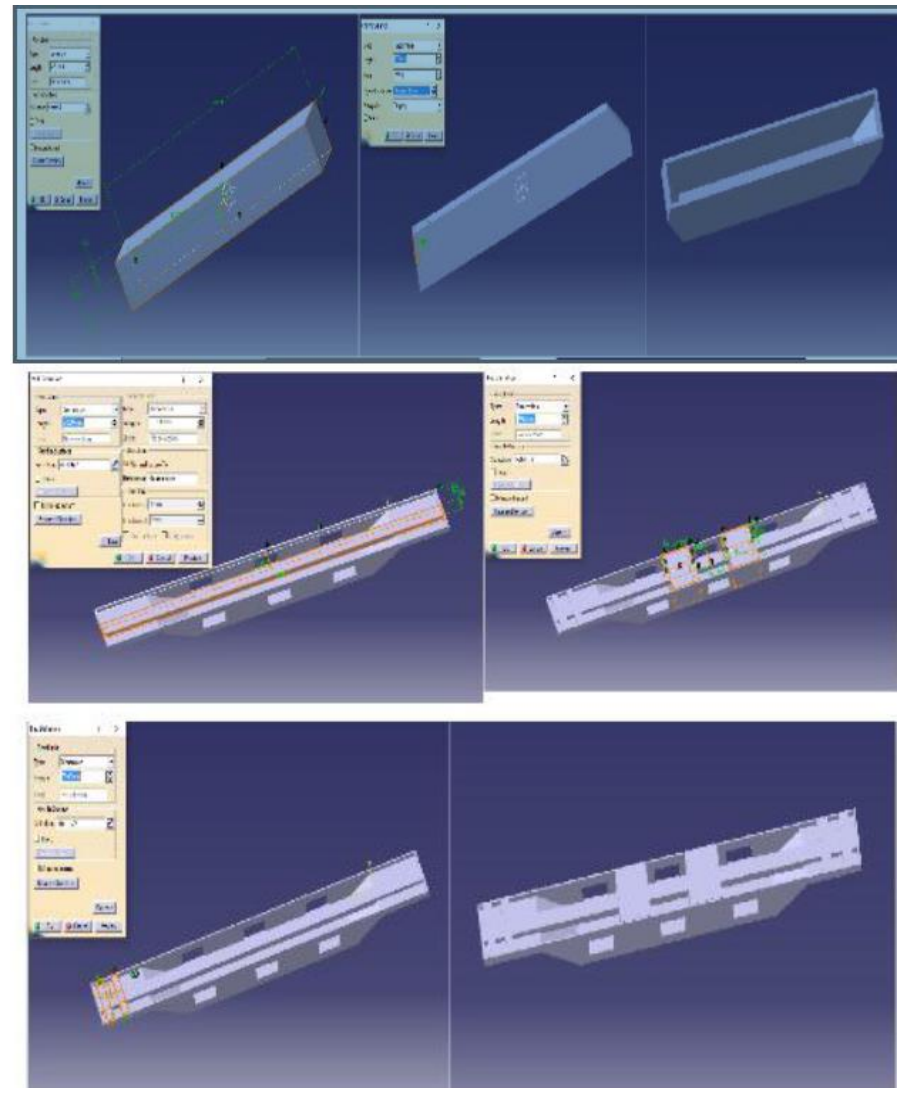

Fig 4.2 Modelling of a railway wagon using software.

Assembly: the assembly includes the combining of the all the parts which are designed or modeled from the pro/e this assembled part further goes to the analysis hear the two types static analysis and dynamic analysis. From static analysis the maximum von mises stress value and maximum comparing von-mises with yield stress of material, factor of safety can be calculated. And from the dynamic analysis values of the lateral and vertical forces, derailment quotient, longitudinal and lateral creep forces coming on tangent and curve track.

\subsection{Load Calculations}

During design stage, possible loads are regularized by a design code. For the present axle, the loads by the code EN 13103 are applied. As shown as in Fig. 1, the loads set is constructed from the vehicle dynamic behavior of the mass $m 1$ above each wheel set with a vertical dynamic factor $\alpha \mathrm{v}$ and a lateral dynamic factor $\alpha \mathrm{H}$, which are respectively defined as 


\section{International Journal of Engineering Applied Sciences and Technology, 2020 \\ Vol. 4, Issue 10, ISSN No. 2455-2143, Pages 122-129 \\ Published Online in February 2020 in IJEAST (http://www.ijeast.com)}

$$
\left\{\begin{array}{l}
V=\left(1+\alpha_{\mathrm{v}}\right) m_{1} g \\
H=\alpha_{\mathrm{H}} m_{1} g
\end{array}\right.
$$

Where $\mathrm{g}$ is gravity acceleration, and the mass $\mathrm{m}_{1}$ can be deduced as

$$
\mathrm{m}_{1}=\left(2 \mathrm{P}-\mathrm{m}_{2} \mathrm{~g}\right) / \mathrm{g}
$$

Using the sample wagon parameters, the loads set for the present check of axle reliability is given:
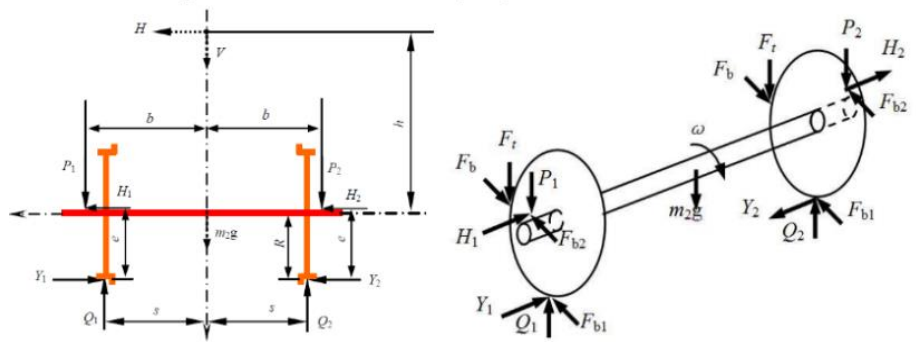

Fig 1.5 Arrangement of wheels.

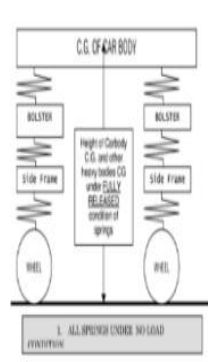

\section{Specifying Centre of Gravity height for two stage suspension}

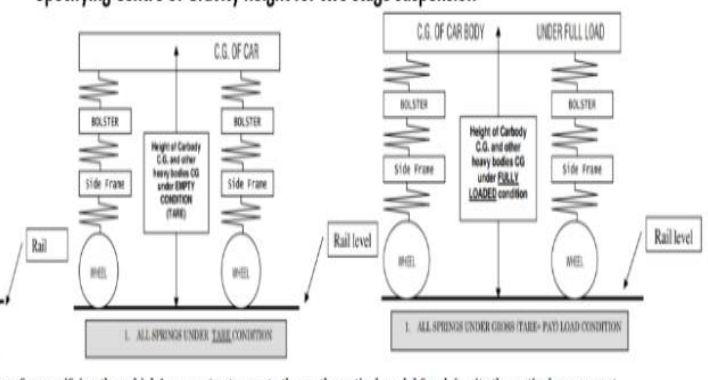

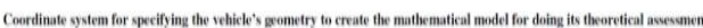
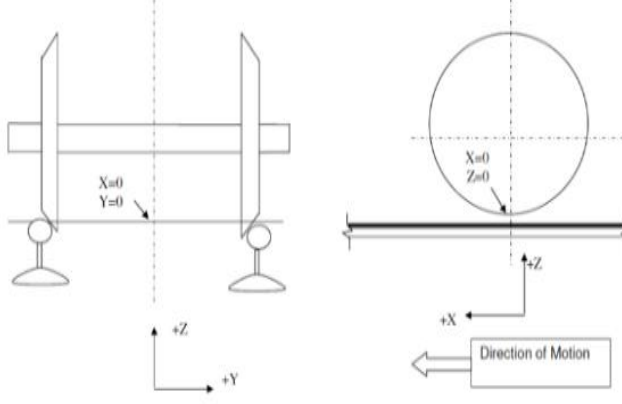

Consideration Based Upon

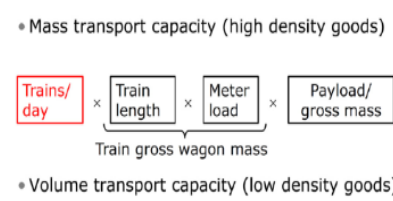

- Volume transport capacity (low density goods)

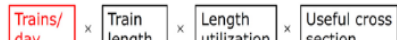

\begin{tabular}{l}
$\begin{array}{l}\text { Trains/ } \\
\text { day }\end{array} \times \begin{array}{l}\text { Train } \\
\text { length }\end{array} \times \begin{array}{l}\text { Length } \\
\text { utilization }\end{array} \times \begin{array}{l}\text { Useful cross } \\
\text { section }\end{array}$ \\
\hline
\end{tabular}

General model of railway system transport capacity infrastructure (fixed asset) perspective
- Mass transport capacity (high density goods)

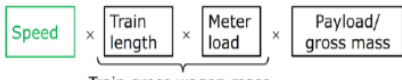

Train gross wagon mass

- Volume transport capacity (low density goods)

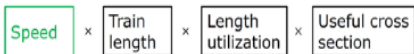

General model of railway system transport capacity - train operating (moving asset) perspective
4.5 Design Methodology:

These are the Steps which are involved in Design

\subsubsection{Deviation of Problem into modules}

Various stages involved in new wagon design are as under:
a) Stage I - Concept Design
b) Stage II - Detailed Design
c) Stage III - Prototype Manufacturing, Testing, Design Validation \& Optimum Speed
d) Stage V - Introduction of new Wagons in Open Line

\section{Criteria for wagon Design (or) Design Methodology:}

\section{Stage I - Concept Design:}

- General arrangement diagram

- Necessary drawing showing dimensions of the wagons

- Type of Commodity and load distribution

- Design considerations like factor of safety, dynamic augment, fatigue allowance criteria (general or component specific)

- Fatigue life of components in Kms or in number of Years.

- Suitability of loading/unloading methods and equipment for the existing facilities on IR system.

- Type of Material used in Wagon Construction i) Type of Wagon: General Purpose, Commodity Specific, Route Specific

- Precaution which should be taken for the complete cycle from loading to unloading to take care

- Of the working conditions/problems in the proposed design.

\section{Stage II - Detailed Design.}

\section{a.) Wagon body}

i) Product structure plan, which shows how the key elements such as components, sub-assemblies \& assemblies form the final product.

ii) Design drawings of key elements which show the main principle of design accompanied by a short description \& as far as necessary for understanding of the design.

iii) Criteria for the selection of materials \& methods for their evaluation. (If such materials are in use in other existing wagons, it should be mentioned.)

iv) Details of various structural joints.

v) Minimum use of riveting shall be made. The DP should submit details for justifying the requirement/necessity of riveting in the wagon design.

b.) Bogie, including its components e.g. axle bearing, wheel \& axle, etc.

c.) Brake system the wagon shall be fitted with graduated release air brake system as per the latest specifications. The brake linkage can be under frame/body or bogie mounted arrangements.

d.) Coupler \& draft gear the proposed wagon designs shall be with standard coupler and draft gear to specification compatible, as 


\section{International Journal of Engineering Applied Sciences and Technology, 2020 \\ Vol. 4, Issue 10, ISSN No. 2455-2143, Pages 122-129 \\ Published Online in February 2020 in IJEAST (http://www.ijeast.com)}

per standard specifications.

e.) Loading and unloading systems

i) Details of operation and fitment of loading and unloading systems on the proposed wagon design

ii) The above-mentioned details to be given for each type of commodity to be transported by the proposed wagon.

iii) Details of Manufacturer of the loading and unloading systems.

\section{Stage III - Prototype Manufacturing, Testing and design} Validation \& Provisional Speed.

a) Standards used for design and calculation

b) Computer programs used for design $\&$ calculation

c) The test schedule should reflect material, components, sub - assemblies, assemblies \& the finished product and will distinguish between: o Type acceptance tests, Production Tests \& Quality Check Tests o Test on first article or on further wagons with test sequence o Location of test site i.e. contractors works, etc.

\section{Stage IV- Oscillation Trial.}

Oscillation trials of the prototype wagon shall be conducted to confirm that the design will exhibit running characteristics as per the limits specified by Criteria.

\section{Stage V - Introduction of new Wagons in Open Line.}

Any design modification be required to be made in any part of the equipment at any time, it will be advised to the DP, who will ensure its compliance for the existing wagons and new wagons, under manufacture.

\subsubsection{BASIC DESIGN PARAMETERS OF PROPOSED WAGON DESIGN}

Table 4.1. Parameters Specifications

\begin{tabular}{|cl|}
\hline \multicolumn{1}{|c|}{ Parameters } \\
\hline A. & General \\
\hline 1. & Axle Load (in tonnes) \\
\hline 2. & TLD (in tonnes/meter) \\
\hline 3. & Tare weight of complete wagon (in tonnes) \\
\hline 4. & Payload of a wagon (in tonnes) \\
\hline 5. & Payload to tare weight ratio \\
\hline 6. & Numbers of wagon in 626 meter length \\
\hline 7. & Payload of rake in 626 meter length (in tonnes) \\
\hline 8. & $\begin{array}{l}\text { Height of C.G. in empty and loaded conditions for } \\
\text { commodities proposed to be loaded (in millimetres) }\end{array}$ \\
\hline 9. Commodity for which wagon is designed \\
\hline 10. Other commodities, which may be carried in the \\
wagon
\end{tabular}

\begin{tabular}{|ll|}
\hline B. & Overall Dimensions (millimetres) \\
\hline 1. & Length over coupler faces \\
\hline 2. & Inside Length \\
\hline 3. & Length between bogie centres \\
\hline 4. & Length over head stock \\
\hline 5. & Coupler height over level Track from rail level \\
\hline 6. & Overall Width \\
\hline 7. & Inside Width \\
\hline 8. & Floor height from rail level \\
\hline 9. Inside height \\
\hline 10. Volumetric Capacity (in cubic meter) \\
\hline 11. Volumetric Capacity of heap Loading (in cubic meter) \\
\hline 12. Total Volumetric Capacity (in cubic meter) \\
\hline
\end{tabular}

\subsubsection{TECHNICAL DATA OF THE PROPOSED WAGON DESIGN}

Table 4.2. Technical Data

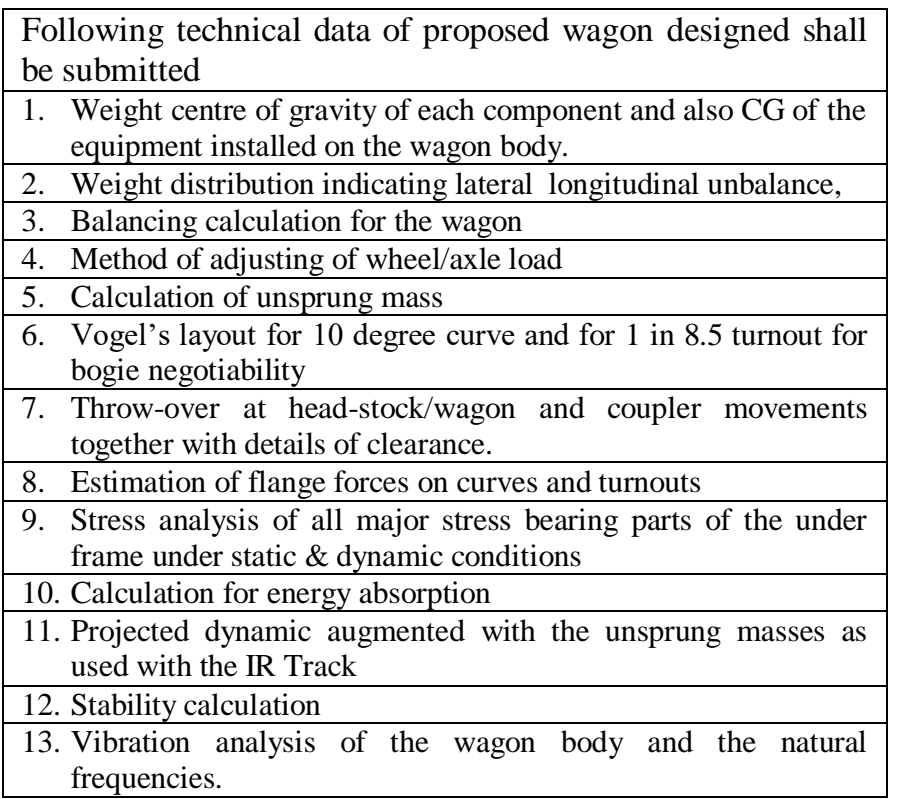

\section{ECONOMICAL FEASIBILITY}

This method is completely in the favor of Prototyping economy; its components are designed by software and can be easily assembled. By using this method we can save time and part of money in field of wagon prototyping.

\section{CONCLUSION}

Modelling: according to dimensions the model of hopper wagon made up of steel and aluminium, the mass momentum of the car body, wheel axle set are been designed by using pro/e software and cad software. From the comparison of steel and aluminium material hopper wagon alloy of these two gives the best result of having the litter weight, less stress acting are acting due to this the train is going to move in the safe way.

Assembly: the assembly includes the combining of the all the parts which are designed or modelled from the pro/e this assembled part further goes to the analysis hear the two types static analysis and dynamic analysis. From static analysis the maximum von mises 


\section{International Journal of Engineering Applied Sciences and Technology, 2020 \\ Vol. 4, Issue 10, ISSN No. 2455-2143, Pages 122-129 \\ Published Online in February 2020 in IJEAST (http://www.ijeast.com)}

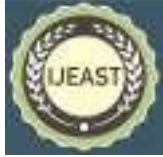

stress value and maximum comparing von-mises with yield stress of material, factor of safety can be calculated. And from the dynamic analysis values of the lateral and vertical forces, derailment quotient, longitudinal and lateral creep forces coming on tangent and curve track from the comparison of steel and aluminium material hopper wagon, the percentage reduction in vertical and normal forces, longitudinal and lateral creep forces by using aluminium material of is calculated.

- Reduction in wheel set vertical force is $8.2 \%$

- Reduction in lateral creep force is 4.6 to $7.32 \%$

- Reduction in longitudinal creep force is 5.99 to $7.65 \%$

- Reduction in wheelset normal force is 4.7 to $8.5 \%$

So it is to be conclude from the above results that aluminium is better and economical than steel.

\section{- Present Conflict}

By using this process, A real time analysis of protype is to be find which reflects the optimized environment for analysis and according to that the Prototype can be developed at the minimum of cost and time.

\section{- Future Scope}

To increasing load carrying capacity of freight wagons, to reduce self-weight of freight wagon to reduce fuel required, to increase speed of the train in tangent track and in curve passing, to increase comfort and safety of passenger coach. So we can use this method for different types of wagons and virtual software analysis of prototype of wagons can be done.

\section{ACKNOWLEDGEMENT}

We are over helmed in all humbleness and gratefulness to acknowledge our depth to all those who have helped me to put these ideas, well above the level of simplicity and into something concrete.

We would like to express our sincere gratitude to our Guide Dr. M. Maniraj \& Industrial Guide Mr. Vishal Pratap Singh for providing their invaluable guidance, comments and suggestions throughout the course of the project. We have taken efforts in this project. However, it would not have been possible without the kind support and help of many individuals and organization Faculties. Whose guidance, encouragement, Suggestion and very constructive criticism have contributed immensely to the evolution of ideas on project. We would like to extend our sincere thanks to all of them.

We are highly indebted to Project Co-Coordinator Mr. Srikant Vidya for their guidance and constant supervision as well as for providing necessary information regarding the project $\&$ also for their support in completing the project.

We would like to express my gratitude towards Faculty member of Galgotias University for their kind co-operation and encouragement which help me in completion of this project.

We would like to express my special gratitude and thanks to Lab and Workshop In-charges for giving me such attention and time.

Our thanks and appreciations also go to my colleague in developing the project and people who have willingly helped me out with their abilities. and helped me a lot in gathering different information, collecting data and guiding me from time to time in making this project, despite of their busy schedules, they gave me different ideas in making this project unique.

\section{REFERENCES}

1. S. S. Harak, S. C. Sharma, S. P. Harsha (2014). Structural dynamic analysis of freight railway wagon using finite element method. Procedia Materials Science 6 ( 2014 ) 1891 1898.

2. H. E. Boysen (2012). General model of railway. WIT Transactions on The Built Environment, Vol 127, ISSN 1743-3509 (on-line) 335-347

3. B. Vinod Kumar, M.Suneetha, Dr.N.Venkatachalapathi (2017). Modeling and Analysis of Railway Wagon. International journal \& magazine of engineering, technology management and research Vol. 4 issue 11 403-407.

4. Krason Wieslaw et al. (2016). Innovative project of prototype railway wagon and intermodal transport system. Transportation Research Procedia 14 ( 2016 ) 615 - 624.

5. S. V. GANORKAR et al. (2017). Innovation Challenge For Indian Railways. Journal Of Information, Knowledge And Research In Mechanical Engineering Vol. 4 (2017) 879-887

6. A.S. XUE ET AL. (2013). Design Reliability Assessment on the Railway Wagon Axle with 30 TonAxle Weigh. Advanced Materials Research Vol. 658(2013) 323-326

7. Stanislav Hodas et al. (2015). Design of Railway Track for Speed and High-speed Railways. ScienceDirect 332-343

8. D. Peng, R. Jones and D. Hui (2016). An Engineering Approach To The Fracture Assessment Of Hopper Wagons. An Engineering Approach To The Fracture S0013-7944(16)30432-5 432-48

9. Vladimir Milovanovic' $\Uparrow$, Vladimir Dunic' , Dragan Rakic', Miroslav $Z^{\smile}$ ivkovic (2015) Identification causes of cracking on the underframe of wagon for containers transportation Fatigue strength assessment of wagon welded joints. Engineering Failure Analysis 31 (2013) 118-131

10. Mehdi Koohmishi et al. (2018) Effect of gradation and size of foulding materials on hydraulic conductivity of sand-fouled railway ballast. Journal of Construction and building material Vol. 6 (2018) 89-97

11. Lukas Lestinsky et al. (2019) New methods of noise reduction in railway carriages. Transportation Research Procedia 40 (2019) 778-783. 